OPEN ACCESS

Edited by:

Irit Ben-Aharon,

Rambam Health Care Campus, Israel

Reviewed by:

Helmut Friess,

Technical University of

Munich, Germany

Xinliang Lu,

Zhejiang University, China

*Correspondence:

Shuan Rao

raoshuan1@smu.edu.cn

Kaican Cai

caican@smu.edu.cn

tThese authors have contributed equally to this work

Specialty section:

This article was submitted to

Gastrointestinal Cancers,

a section of the journal

Frontiers in Oncology

Received: 30 March 2020

Accepted: 03 August 2020 Published: 10 September 2020

Citation:

Yang J, Liu X, Cao S, Dong X, Rao S and Cai $K$ (2020) Understanding

Esophageal Cancer: The Challenges and Opportunities for the Next Decade. Front. Oncol. 10:1727. doi: 10.3389/fonc.2020.01727

\section{Understanding Esophageal Cancer: The Challenges and Opportunities for the Next Decade}

\author{
Jianjun Yang ${ }^{\dagger}$, Xiguang $\mathrm{Liu}^{\dagger}$, Sai Cao, Xiaoying Dong, Shuan Rao* and Kaican Cai* \\ Department of Thoracic Surgery, Nanfang Hospital, Southern Medical University, Guangzhou, China
}

Esophageal cancer (EC) is the seventh most common cancer worldwide with over 570,000 new cases annually. In China, the incidence of EC is particularly high where approximately $90 \%$ of cases are defined as esophageal squamous cell carcinoma (ESCC). Although various risk factors have been identified, the knowledge of genetic drivers for ESCC is still limited due to high mutational loading of the cancer and lack of appropriate EC models, resulting in inadequate treatment choices for EC patients. Currently, surgery, chemotherapy, radiation, and limited targeted therapy options can only bring dismal survival advantages; thus, the prognosis for ESCC is very poor. However, cancer immunotherapy has unleashed a new era of cancer treatment with extraordinary therapeutic benefits for cancer patients, including EC patients. This review discusses the latest understanding of the risk factors and clinical rational for EC treatment and provides accumulated information, which describes the ongoing development of immunotherapy for EC with a specific emphasis on ESCC, the most prevalent EC subtype in the Chinese population.

Keywords: epidemiology, esophageal cancer, risk factors, genetics, clinical management, immunotherapy

\section{INTRODUCTION}

Esophageal cancer (EC) is ranked as the seventh most common cancer worldwide with over 570,000 new cases in 2018 (1). The pathology of EC is relatively less understood compared to many other cancers, and it usually shows extremely aggressive clinical features when diagnosed; thus, it is known that EC is the sixth leading cause of malignancy-related death with a 5-year survival ratio of $15-20 \%(1)$.

There are two major subtypes of EC, esophageal squamous cell carcinoma (ESCC) and esophageal adenocarcinoma (EAC), which usually occur in either proximal ESCC or distal esophagus EAC, respectively (2). Although ESCC is the predominant pathological type of EC, the incidence of ESCC and EAC can be very different among different countries and regions (3). For instance, ESCC patients account for $90 \%$ of cases in China, Japan, and southeast Africa countries (4-6); however, EAC is more prevalent in the United States, Australia, and Western European countries (7-9). Recently, accumulated evidence has suggested that ESCC and EAC are actually two different diseases $(10,11)$, as they have quite different risk factors and genetic profiles; however, EAC is more comparable to gastroesophageal junction carcinomas (GEJCs) or gastric cancer (GC). In this review, we will particularly discuss ESCC, the subtype diagnosed for more than 250,000 patients every year in China. 


\section{THE EPIDEMIOLOGY OF ESOPHAGEAL CANCER IN CHINA}

Esophageal cancer is a significant public health burden in China, although some recent studies have indicated that the incidence of EC is decreasing in the last few decades. In 2012, China contributed nearly half of the global new EC patients. Briefly, EC was the fifth most frequently diagnosed cancer and the fourth leading cause of cancer-related death in China, with estimated 286,700 new and 211,000 death cases (12). Another study indicated that there were 276,900 newly diagnosed and 206,500 death EC cases in 2013; the incidence was $28.15 / 10^{5}$ and $12.15 / 10^{5}$ in male and female, respectively (13), which decreased to $26.46 / 10^{5}$ and $10.85 / 10^{5}$ in 2014 (14). Furthermore, in 2015 , it was estimated that the occurrence of EC was $17.87 / 10^{5}$ and a rough mortality of $13.68 / 10^{5}$ in the Chinese population (15). Indeed, the statistics from the National Central Cancer Registry of China (NCCRC) also showed a decreasing trend of EC incidence and mortality in both male and female populations from 2000 to 2013 (13). Of note, the incidence and mortality of EC were quite different among different regions in China. Provinces near the Taihang Mountains, such as Hebei, Henan, and Chongqing had a relatively higher EC incidence, whereas in Xinjiang, Jiangsu, Shanxi, Gansu, and Anhui, the EC reported cases were much less (16).

ESCC is the predominant histological subtype of EC in China, accounting for $88.84 \%$ of all EC cases in the Chinese population (17). Although increasing survival of EC patients were observed in both population-based and hospital-based studies $(18,19)$, the prognosis for ESCC/EC in China is relatively poor when compared to other cancers, as most studies reported that EC patients had a 5-year survival rate between 15 and 25\% $(20,21)$. In a population-based study including 1,033 ESCC patients who received surgery, patients in stages IA, IB, IIA, IIB, IIIA, IIIB, IIIC, and IV had a 5-year survival rate of $84.9,70.9,56.2,43.3$, $37.9,23.3,12.9$, and $3.4 \%$, respectively (22). Similar findings were reported in another Chinese population-based study (23). Importantly, the survival for those ESCC patients with distant organ metastasis at the first diagnosis is particularly poor, as a retrospective study indicated that these patients had a median survival of only 6 months with 1 - or 2-year survival rates of 21.1 or $11.8 \%$ (24), respectively. Furthermore, hospital-based studies also suggested that the 5-year survival rate of EC patients was $<20 \%(19,25)$.

\footnotetext{
Abbreviations: EC, esophageal cancer; ESCC, esophageal squamous cell carcinoma; EAC, esophageal adenocarcinoma; GEJC, gastroesophageal junction carcinomas; GC, gastric cancer; NCCRC, National Central Cancer Registry of China; IARC, the International Agency for Research on Cancer; RR, risk ratio; $\mathrm{CI}$, confidence interval; $\mathrm{OR}$, odds ratio; $\mathrm{ADH}$, alcohol dehydrogenase; GERD, gastroesophageal reflux disease; SIR, standardized incidence ratio; IRR, incidence rate ratio; BMI, body mass index; WES, whole exome sequencing; WGS, whole genome sequencing; CT, chemotherapy; RT, radiotherapy; CRT, chemoradiotherapy; OS, overall survival; EGFR, epidermal growth factor receptor; hEGFR, human epidermal growth factor receptor; PI3K/mTOR, phosphoinositide 3-kinase/mammalian target of rapamycin; anti-PD-L1, anti-programmed cell death 1 ligand 1; anti-PD-1, anti-programmed cell death 1; anti-CTLA4, anticytotoxic T lymphocyte-associated antigen-4; PFS, progression-free survival; PDO, patient-derived organoid.
}

\section{RISK FACTORS OF EC}

The investigation of the risk factors of EC has been carried out for many years. Surprisingly, the risk factors' profiles for ESCC and $\mathrm{EAC}$ are quite different even in the same population or the same area (Figure 1).

\section{Smoking}

Tobacco smoking is a risk factor for both ESCC and EAC all around the world, and it was defined as one major cause of EC by the International Agency for Research on Cancer (IARC) (26). Intriguingly, tobacco smoking is more significantly associated with the incidence of ESCC than that of EAC (27). For current smokers, the risk of ESCC increased from three to seven times than those who never smoked $(27,28)$. Another meta-analysis including 52 studies indicated that the risk of ESCC was dramatically higher in current smokers [risk ratio (RR): 4.18, 95\% CI: 3.42-5.12] compared to non-smokers (29). In contrast, smoking cessation could apparently reduce the risk of esophageal carcinogenesis. A reduction in ESCC's risk in eversmokers was evident after 5 years of termination of smoking when compared to current smokers (RR: 0.59 , 95\% CI: $0.47-$ $0.75)$, and this difference was even more significant 10 years (RR: 0.42 , 95\% CI: $0.34-0.51$ ) and 20 years (RR: 0.34, 95\% CI: 0.25-0.47) after smoking cessation (29).

Similarly, tobacco smoking can also elevate the risk of EAC, although the association is not as strong as that of ESCC. Smokers had a nearly 2 fold higher risk of EAC $(27,30)$. However, the risk of EAC did not show any decrease in ever-smokers after smoking cessation, with a risk ratio of 0.72 (95\% CI: $0.52-1.01$; follow up for 20 years or longer after smoking cessation) compared to current smokers (29).

\section{Alcohol Consumption}

The effect of alcohol overconsumption on EC carcinogenesis has been widely recognized. In America, over 70\% of ESCC patients had alcohol consumption histories (95\% CI: 53.3-85.8\%) (31). One meta-analysis including 92,000 light drinkers and 60,000 non-drinkers suggested that light drinking increased the risk of ESCC (RR: 1.30; 95\% CI: 1.09-1.56), and it was estimated that 24,000 deaths from ESCC were attributed to alcohol drinking globally in 2004 (32). In line with this study, by adjusting age, sex, and tobacco smoking, it was reported that the relative risks of ESCC among light drinkers ( $\leq 12.5 \mathrm{~g} /$ day), moderate drinkers (12.5-50 g/day), and heavy drinkers ( $\geq 50 \mathrm{~g} /$ day) were $1.38(95 \%$ CI: 1.14-1.67), 2.62 (95\% CI: 2.07-3.31), and 5.54 (95\% CI: 3.92-7.28) compared to non-drinkers, respectively (33).

In China, one study carried out in Huaian, Jiangsu Province, suggested that liquor intake significantly increased the risk of esophageal precancerous lesions [odds ratio (OR): 3.22, 95\% CI: 1.28-8.13] (34). Another study suggested that alcohol drinking increased the risk of ESCC by 1.953 -fold in the Chinese population (35). Interestingly, $\mathrm{Wu}$ et al. reported that consumption of alcohol only increased the risk of ESCC in males but not in females (36), as supported by another study that indicated that only males who drank alcohol had a 2.2-fold (95\% 


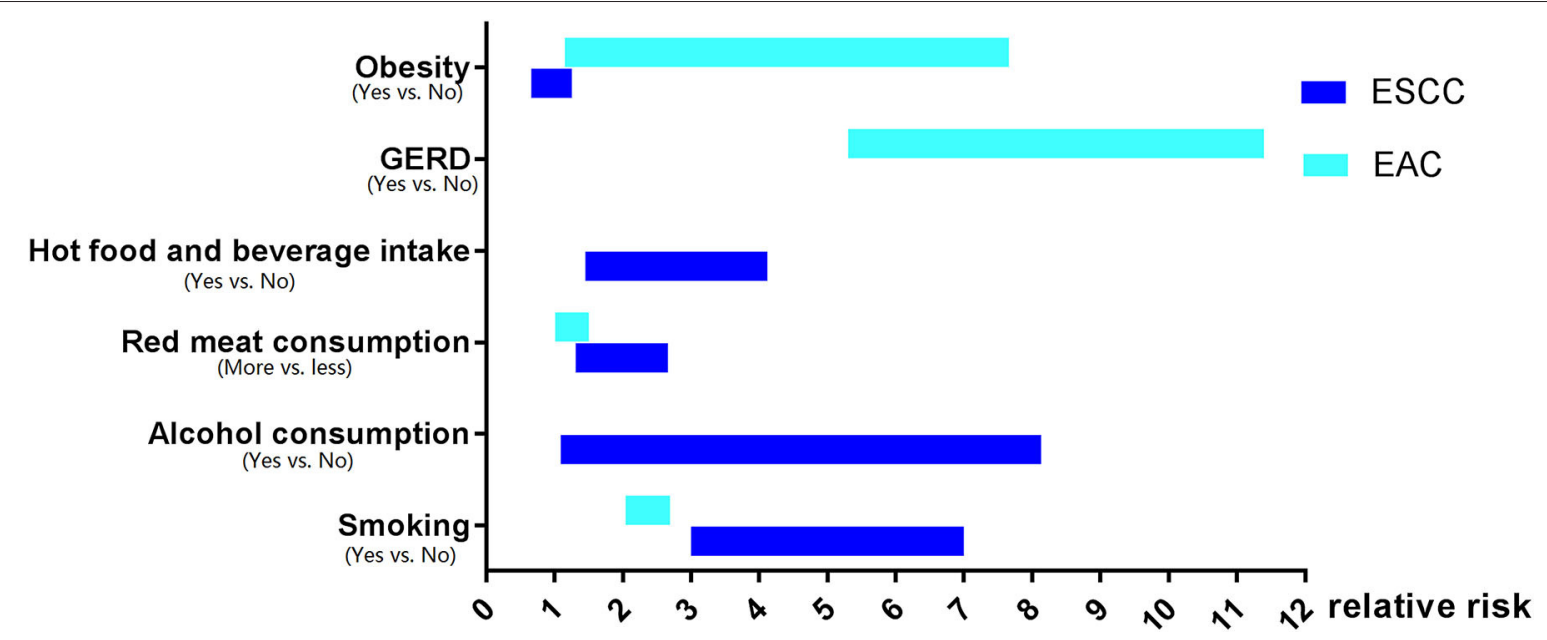

FIGURE 1 | The risk factors profiles for esophageal squamous cell carcinoma and esophageal adenocarcinoma.

CI: 1.79-2.70) higher ESCC risk (37). Mechanistically, a casecontrol study that enrolled 1,190 patients and 1,883 controls revealed that alcohol consumption could interact with aldehyde dehydrogenase and alcohol dehydrogenase $(\mathrm{ADH})$, resulting in a markedly elevated ESCC incidence (38).

Intriguingly, till now, neither population-based nor hospitalbased studies can determine the association between the susceptibility of EAC and alcohol consumption. According to a pool analysis including 1,821 EAC patients and 10,854 controls, alcohol did not increase the risk of EAC even for heavy drinkers who had more than seven drinks per day ( $14 \mathrm{~g}$ of ethanol per drink), whereas this study also indicated that alcohol drinking was significantly associated with an increased risk of ESCC (OR for drinkers more than seven drinks per day: 9.62, 95\% CI: 4.26-21.71) (39).

\section{Dietary}

Dietary has been well-defined as the risk factor for EC. Low fruit and vegetable intake accounted for $28.7 \%$ (95\% CI: $11.1-56.5 \%)$ of ESCC and $15.3 \%$ (95\% CI: $5.8-34.6 \%$ ) of EAC cases (31). Moreover, increasing diversities of vegetables and fruits could significantly decrease the risk of ESCC, particularly in smokers; however, this phenomenon is not applicable for EAC (40).

Notably, pickled vegetables are also reported to contribute to the carcinogenesis of ESCC, as one study in Jiangsu Province, China, suggested that ingestion of pickled food was correlated with higher incidence of esophageal precancerous lesion (34). Furthermore, another meta-analysis that included 34 studies revealed that consumption of pickled vegetables increased the risk of ESCC $\sim 2$ times (41).

Moreover, it was shown that the relative risk of ESCC for people who had more red meat or processed meat was $1.57(95 \%$ CI: $1.26-1.95)$ or 1.55 (95\% CI: 1.22-1.97) compared to people who had less meat consumption (42). This finding was further supported by another pool analysis including seven cohorts and 28 case-control studies, which also indicated that high red meat intake as well as low poultry intake increased the risk of ESCC. Interestingly, high meat consumption, particularly processed meat, was associated with an elevated EAC risk (43).

\section{Hot Food and Beverage}

Numerous studies have identified that hot food and beverage can obviously increase the risk of EC (34, 44-46). A case-control study in northwest China suggested that the OR of ESCC risk among people who preferred hot tea, water, or hot food was 2.23 (95\% CI: 1.45-2.90), 2.13 (95\% CI: 1.53-2.66), or 2.98 (95\% CI: 1.89-4.12), respectively (47). Another study reported that hot beverage, including tea and coffee, increased 2- to 4 fold the risk of EC (44). By adjusting confounding variables, it was demonstrated that intake of hot food and beverage was significantly correlated with a higher risk of ESCC, but not with EAC (46).

\section{Gastroesophageal Reflux Disease}

The prompting effect of gastroesophageal reflux disease (GERD) on EAC carcinogenesis has been very well-characterized. In a medical record-based, case-control study, patients who had a history of GERD had a 2 fold or even higher risk of EAC (47). Another population-based, case-control study suggested the OR of EAC risk among people with recurrent reflux symptom was 7.7 (95\% CI: 5.3-11.4) when compared with other people without this symptom (48). Such effect of GERD on EAC carcinogenesis was also observed in a retrospective study in Swedish, as the standardized incidence ratio (SIR) of EAC among GERD patients who did not receive surgery was 6.3 (95\% CI: 4.5-8.7) (49). Another meta-analysis including five independent studies revealed that the OR of EAC among patients with weekly or daily GERD symptoms was 4.92 (95\% CI: 3.90-6.22) or 7.40 (95\% CI: 4.94-11.1), respectively (50). Thus, GERD is a key risk factor of EAC; however, no evidence has been found so far to unveil the correlation between GERD and ESCC carcinogenesis. 


\section{Obesity}

Obesity is another confirmed risk factor for EAC. According to the NIH-AARP Diet and Health study, the hazard ratio (HR) of EAC for people with the highest body mass index (BMI) $(\geq 35$ $\mathrm{kg} / \mathrm{m}^{2}$ ) was $2.11(95 \% \mathrm{CI}: 1.09-4.09)$ compared to people with the lowest BMI $\left(<18.5 \mathrm{~kg} / \mathrm{m}^{2}\right)(51)$. In line with this finding, a pool analysis revealed that the ORs of EAC for people with BMIs of $25-29.9,30-34.9,35-39.9$, and $\geq 40 \mathrm{~kg} / \mathrm{m}^{2}$ were $1.54(95 \%$ CI: 1.26-1.88), 2.39 (95\% CI: 1.86-3.06), 2.79 (95\% CI: $1.89-$ 4.12 ), and 4.76 (95\% CI: $2.96-7.66)$, respectively, compared to people with normal BMI $\left(<25 \mathrm{~kg} / \mathrm{m}^{2}\right)$ (52). Intriguingly, obesity appears to be inversely associated with the risk of ESCC. In a prospective cohort study involving more than 220,000 Chinese, increasing BMI was correlated with decreasing ESCC mortality (53). Consistently, another study in China also suggested that the ESCC HR for people with BMI $<18.5,24-28$, and $\geq 28 \mathrm{~kg} / \mathrm{m}^{2}$ was 1.21 (95\% CI: 1.02-1.43), 0.87 (95\% CI: 0.78-0.98), and 0.91 (95\% CI: 0.66-1.25), respectively (54).

\section{Socioeconomic Status}

Surprisingly, low socioeconomic status, namely, low income and education, is associated with a higher risk of ESCC. According to a prospective study that enrolled 29,584 individuals in China, participants who received education of 1 to 5 years, completed primary school or middle school education had an RR of ESCC for 0.87 (95\% CI: 0.77-0.89), 0.78 (95\% CI: 0.64-0.94), or 0.57 (95\% CI: $0.45-0.73$ ), respectively, when compared to people without formal education (55). A similar phenomenon was also observed in a case-control study in Iran, as the adjusted ORs of ESCC for people with primary education and high school or beyond were 0.52 (95\% CI: $0.27-0.98$ ) and 0.20 (95\% CI: 0.06-0.65), respectively, compared to non-educated people (56). Low income is also associated with an elevated ESCC risk. In a Swedish population-based cohort study that enrolled 4,734,227 individuals, participants with a high income had an EC incidence rate ratio (IRR) of 0.74 (95\% CI: $0.70-0.79)$ for men and 0.83 (95\% CI: 0.76-0.91) for women when compared to low-income people (57).

Low socioeconomic status was also related to an increased risk of EAC. A case-control study in Swedish suggested that compared to professionals, the risks of EAC were significantly increased in skilled manual workers (OR: 2.4; 95\% CI: 1.1-5.3), assistant nonmanual employees (OR: 2.3; 95\% CI: 1.0-5.3), unskilled manual workers (OR: 3.7; 95\% CI: 1.7-7.7), and self-employed (OR: 3.7; 95\% CI: 1.7-8.1) (58).

To summarize, the risk factors for ESCC and EAC share very limited similarities. Alcohol consumption, pickled vegetables, hot food, and beverage increase the risk of ESCC but not EAC, whereas GERD increases the risk of EAC only. Although smoking, low intake of fruits and vegetables, high consumption of red, or processed meat, as well as low socioeconomic status increase the risk for both ESCC and EAC, smoking has a much stronger effect on the carcinogenesis of ESCC. Of note, obesity seems to play an opposite role in EAC or ESCC development, which facilitates EAC but negatively correlates with ESCC tumorigenesis.

\section{GENETICS OF EC/ESCC}

Many studies have investigated the genetic profiles of ESCC and EAC by whole exome sequencing (WES), whole genome sequencing (WGS), chromosomal analysis, and methylation status evaluation. Surprisingly, these studies indicated that there were quite different mutational landscapes between ESCC and $\operatorname{EAC}(10,11,59,60)$.

\section{ESCC}

Like many other cancers, TP53 mutations are usually identified in ESCC and play an important role in promoting the development of $\operatorname{ESCC}(61,62)$. Recently, a comprehensive molecular characterization of 164 EC specimens was performed to investigate the molecular signature of ESCC and EAC as well as to improve the classification of EC. The results showed that mutations of TP53, CCND1, SOX2, TP63, PIK3CA, PTEN, NFE2L2, MLL2, ZNF750, NOTCH1, MLL2, FGFR1, and RB1 were significantly enriched in ESCC (11), which were consistent with previous studies (63-65). In this analysis, the 90 ESCCs were classified into three subtypes according to their mutation status, including 50 ESCC1, 36 ESCC2, and 4 ESCC3 (11). Specifically, ESCC1 had a similar genetic characteristic to the classical ESCC, including the alteration in the NRF2 pathway, autophagy pathway, and Hippo pathway. For instance, SOX2 and/or TP63 amplification, YAP1 (11q22.1) amplification, VGLL4/ATG7 deletion, and mutation in NFE2L2 were frequently detected in ESCC1; ESCC2 was defined with more alterations in NOTCH1 and ZNF750, CDK6 amplification, inactivation of KDM6A, KDM2D, PTEN, and PIK3R; ESCC3 harbored more activation in the PI3K pathway and somatic alterations of KMT2D, MLL2, and SMARCA4 (11). Ingenuity pathway assessment suggested that gene mutations in ESCC were mainly involved in cell cycle regulation, Notch, RTK-MAPKPI3K, and Wnt pathways (66). Another Chinese WES analysis reported that BRCA2 loss-of-function germline mutations were associated with increased ESCC risk (67). Recently, genes involved in chromatin remodeling and cell cycle regulation, such as CDK11A, ARID1A, JMJD6, MAML3, DKN2AIP, and PHLDA1, were also identified with an elevated risk of ESCC (68).

\section{EAC}

The mutation profile of EAC shares limited similarity with ESCC; however, TP53 mutations are also commonly observed in EAC $(69,70)$. Genomic analysis had revealed that EAC was more similar to gastric cancer in terms of chromosomal instability (71). Unlike ESCC, mutations of ERBB2, VEGFA, EGFR, KRAS, GATA4, SMAD4, CCNE1, GATA6, FGF3/4/19, GATA4/6, CDKN2A, and ARID1A were more frequently recognized in EAC patients (11). Another WES analysis of 149 EAC tumor-normal pairs reported that 26 genes, such as TP53, CDKN2A, SMAD4, ARID1A, PIK3CA, SPG20, TLR4, ELMO1, and DOCK2, were often mutated in EAC, and the activation of the RAC1 pathway contributed to EAC tumorigenesis (72). Meta-analysis of gene expression profiling suggested that EAC could be mainly classified into two subtypes; 24 genes such as SMAD4, SOCS4, and SKAP2 were highly mutated in subtype I 


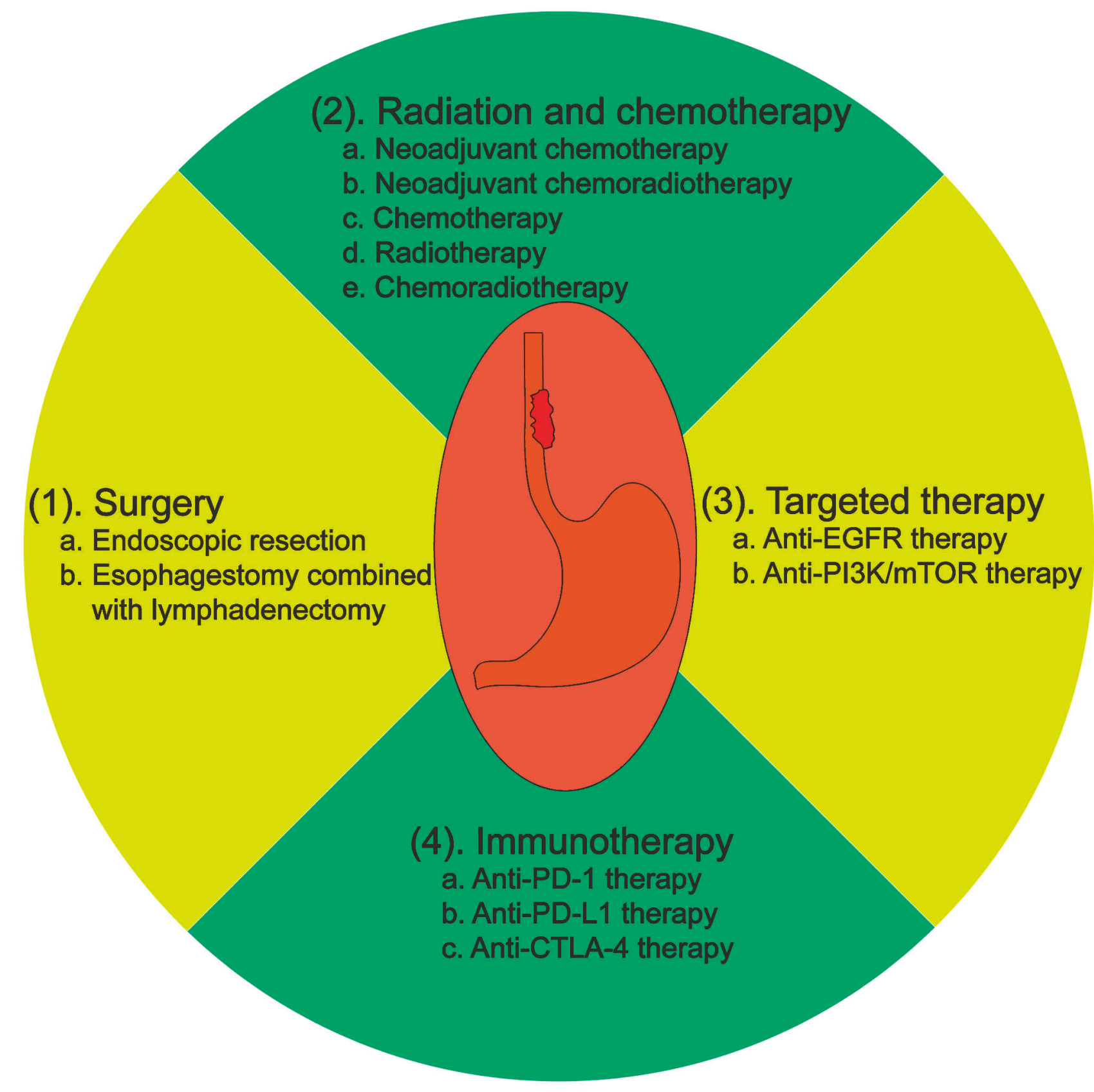

FIGURE 2 | Current treatment options for esophageal cancer.

EAC, whereas the other 30 genes' mutations, including ARID1A, DCDC1, and IVL, were only detected in subtype II EAC (69).

\section{CLINICAL MANAGEMENT OF EC}

Currently, the options for EC patients' treatment are very broad. Multimodality treatments, such as endoscopic resection, surgery, chemotherapy (CT), radiotherapy (RT), chemoradiotherapy (CRT), and targeted therapy, are widely applied worldwide $(2,73)$ (Figure 2).
The treatment strategies are usually determined according to the EC patients' pathological conditions. For early EC limited to the mucosa, endoscopic mucosal resection is the primary treatment option with a 5 -year survival rate of $41 \%$ (74). After the resection, the specimens should be thoroughly examined for the depth of tumor infiltration, and vascular and nerve invasion (74). For resectable EC with muscle or deeper invasion, esophagectomy combined with lymphadenectomy is the primary treatment strategy, while neoadjuvant CT, RT, or CRT is optional. In a randomized controlled study, patients treated with surgery 
plus neoadjuvant CT had a median overall survival (OS) of 16.8 months with a 2 -year OS rate of $43 \%$, exhibiting a better prognosis compared to those patients who received surgery alone with a median OS of 13.3 months and a 2-year OS rate of $34 \%$ (75). Several meta-analyses also suggested that neoadjuvant CT was beneficial to improve OS for EC patients with surgery compared to patients who received surgery alone $(76,77)$. Although no evidence had shown that neoadjuvant RT could bring survival advantages for patients with resectable EC (78), numerous studies had reported that preoperative CRT definitely improved the survival of patients with EC. For instance, a network meta-analysis including 6,072 EC patients indicated that patients who received neoadjuvant CRT with surgery had better survival compared to those patients who underwent CT with surgery as well as those who received surgery alone (79). This study thus suggested that neoadjuvant therapies combined with surgery are superior treatment strategies compared to surgery followed with adjuvant treatments or surgery alone (79).

Whether targeted therapy has a potential effect on the prognosis of EC is also being wildly investigated (Table 1). However, there are only a few options available for EC patients' targeted therapy, most of which are targeting epidermal growth factor receptor (EGFR) (80), human epidermal growth factor receptor 2 (HER2) (81), or phosphoinositide 3-kinase/mammalian target of rapamycin (PI3K/mTOR) (82). COG, a phase 3 parallel randomized placebo-controlled trial, was aiming to evaluate whether gefitinib (an EGFR tyrosine kinase inhibitor) could be applicable for late-stage EC patients. However, it was shown that gefitinib did not improve the OS of unselected patients with EC (80). Besides, in the RTOG 0436 trial, cetuximab, a specific EGFR monoclonal antibody, was added to concurrent chemoradiation therapy for EC patients who were unable to receive esophagectomy. Unfortunately, the addition of cetuximab to concurrent chemoradiation did not improve clinical complete response and OS in either ESCC or EAC (83). In the ToGa trial, 584 patients with gastric cancer or GEJC were randomly assigned to receive chemotherapy alone or chemotherapy plus trastuzumab, a monoclonal antibody that selectively targeted the extracellular domain of HER2. Patients treated with trastuzumab showed slightly better median OS (13.8 vs. 11.1 months, $p=0.0046$ ) (84). Furthermore, in the JACOB trial, 780 patients with metastatic gastric cancer or GEJC were given either pertuzumab (a monoclonal antibody that inhibits HER2) plus trastuzumab in addition to chemotherapy or trastuzumab together with chemotherapy. However, the addition of pertuzumab did not bring any significant survival advantages (85).

Nevertheless, surgery, CT, RT, CRT, or targeted therapy can only bring mild survival advantages to EC patients, making this disease one of the leading causes for cancer-related death.

\section{IMMUNOTHERAPY FOR EC/ESCC}

Recently, immunotherapy has opened a new era for cancer treatment with extraordinary therapeutic benefits in certain cancer patients. Clinically, there are two major immunotherapy options for EC patients, which are anti-programmed cell death 1 ligand 1 (anti-PD-L1)/anti-programmed cell death 1 (anti-PD1) and anticytotoxic T-lymphocyte-associated antigen-4 (antiCTLA-4) therapy. A comprehensive overview for those ongoing clinical trials of immunotherapy for Chinese EC patients are listed in Table 2.

\section{Anti-PD-L1 or Anti-PD-1 Therapy}

PD-L1, a molecule that locates on the tumor cells' surface, can bind to $\mathrm{PD}-1$, which is expressed on the T cells' membrane, resulting in inhibition of $\mathrm{T}$-cell function thus, contributing to tumor cell escape from immunosurveillance (86).

Pembrolizumab is a PD-1 inhibitor, which was first approved by FDA for treating patients with advanced or unresectable melanoma (87). KEYNOTE-028, a multicohort phase IB study, was designed to investigate the potential therapeutic effect of pembrolizumab on patients with PD-L1-positive advanced solid tumors. In the EC cohort, patients were treated with pembrolizumab every 2 weeks for up to 2 years or until confirmed disease progression or intolerable toxicity. The overall response rate was 30\% (95\% CI: $13-53 \%)$, and the median duration of response was 15 months (range from 6 to 26 months) (88). KEYNOTE-180, a phase 2, open-label, interventional, and singlearm study, was designed to evaluate the efficacy and safety of pembrolizumab for advanced, metastatic ESCC, EAC, or gastroesophageal junction adenocarcinoma patients with disease progression after two or more lines of systematic therapies. The objective response rate was 9.9\% (95\% CI: $5.2-16.7 \%$ ) among all patients (12 of 121), while the median duration of response was not achieved (range, 1.9-14.4 months). In detail, the objective response rate was $14.3 \%$ (95\% CI: 6.7-25.4\%) for ESCC patients (9 of 63), 5.2\% (95\% CI: $1.1-14.4 \%$ ) for EAC patients (3 of 58), 13.8\% (95\% CI: 6.1-25.4\%) for all patients with PD-L1-positive tumors (8 of 58), and 6.3\% (95\% CI: $1.8-15.5 \%)$ for all patients with PD-L1-negative tumors (4 of 63) (89), suggesting a quite low response rate of EC patients to anti PD-1/PD-L1 therapy.

\section{Anti-CTLA-4 Therapy}

CTLA-4 is a transmembrane receptor on $\mathrm{T}$ cells, which inactivates early stages of $\mathrm{T}$ cells by interacting with CD80 or CD86 (86). Currently, the immunotherapy targeting CTLA-4 has been wildly used for treating various cancer patients, including EC $(90,91)$. The efficacy of tremelimumab, a monoclonal antibody against CTLA-4, was previously investigated for treating metastatic gastric cancer and EAC patients; unfortunately, a phase II clinical trial that enrolled 18 such patients treated with tremelimumab revealed no effects on progression-free survival (PFS) or OS (92). In the CheckMate032 study, a multicohort, phase I/II trial, 160 patients with locally advanced or metastatic chemotherapy-resistant EC, gastric, or gastroesophageal junction cancer were treated with either (i) nivolumab (3 $\mathrm{mg} / \mathrm{kg}$ ), (ii) nivolumab (1 $\mathrm{mg} / \mathrm{kg}$ ) plus ipilimumab (3 mg/kg), or (iii) nivolumab (3 mg/kg) plus ipilimumab (1 mg/kg). The objective response rates were $12 \%$ (95\% CI: 5-23\%), 24\% (95\% CI: $13-39 \%)$, and $8 \%$ (95\% CI: 
TABLE 1 | Ongoing clinical trials of targeted therapy for esophageal cancer in China.

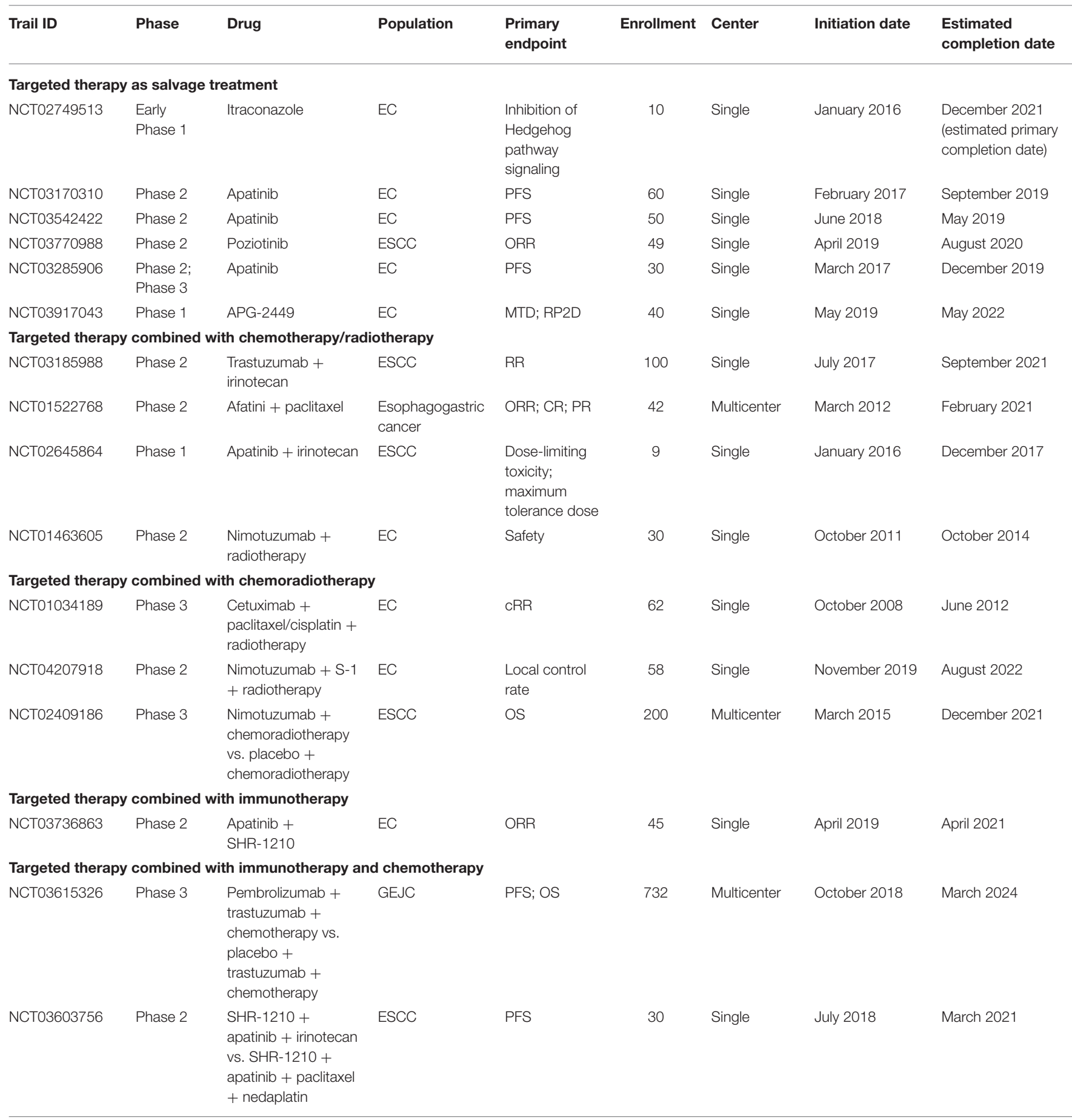

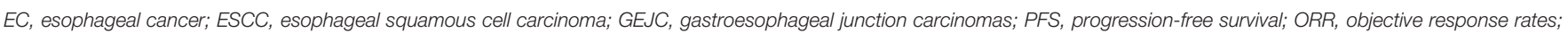

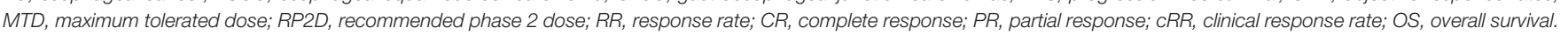

2-9\%), the 12-month PFS rates were 8, 17, and 10\%, and the 12 -month OS rates were 39,35 , and $24 \%$ for the abovementioned three groups, respectively. This study demonstrated for the first time that combined anti-PD-L1/PD1 and anti-CTLA-4 therapy could provide clinical benefits and durable antitumor activity for advanced or metastatic chemotherapy-resistant EC, gastric, or gastroesophageal junction cancer patients (93); however, more randomized controlled trials were required to validate the efficacy and safety of anti-CTLA-4 therapy for EC patients. 
TABLE 2 | Ongoing clinical trials of immunotherapy for esophageal cancer in China.

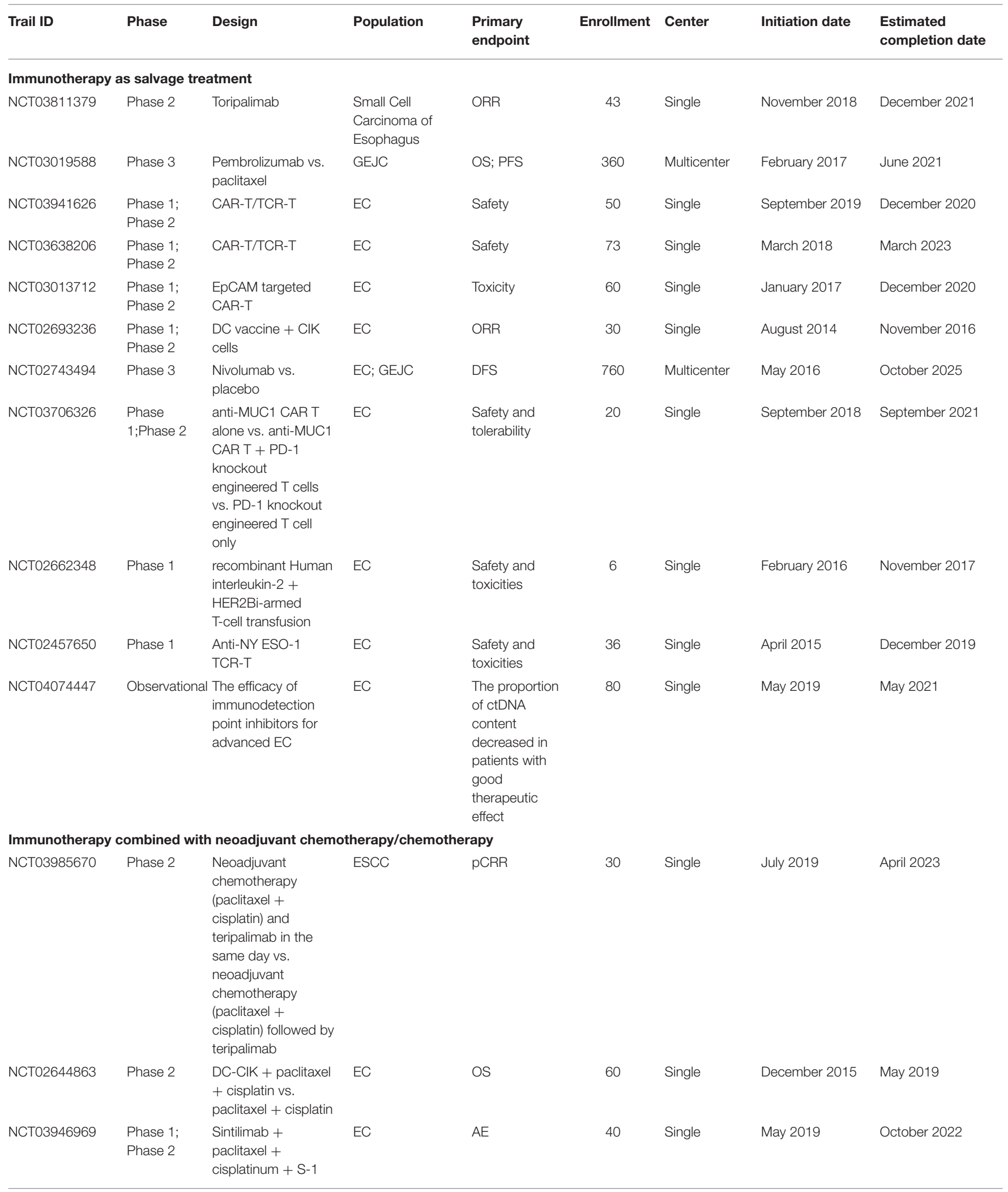


TABLE 2 | Continued

\begin{tabular}{|c|c|c|c|c|c|c|c|c|}
\hline Trail ID & Phase & Design & Population & $\begin{array}{l}\text { Primary } \\
\text { endpoint }\end{array}$ & Enrollment & Center & Initiation date & $\begin{array}{l}\text { Estimated } \\
\text { completion date }\end{array}$ \\
\hline NCT04225364 & Phase 2 & $\begin{array}{l}\text { Camrelizumab + } \\
\text { neoadjuvant } \\
\text { chemotherapy } \\
\text { (paclitaxel + } \\
\text { cisplatin) }\end{array}$ & ESCC & PCR & 50 & single & January 2020 & June 2023 \\
\hline NCT03691090 & Phase 3 & $\begin{array}{l}\text { SHR-1210 + } \\
\text { paclitaxel + cisplatin } \\
\text { vs. placebo + } \\
\text { paclitaxel + cisplatin }\end{array}$ & EC & PFS; OS & 548 & Single & December 2018 & October 2021 \\
\hline \multicolumn{9}{|c|}{ Immunotherapy combined with neoadjuvant radiotherapy/radiotherapy } \\
\hline NCT03011255 & Phase 2 & $\begin{array}{l}\text { Radiotherapy + } \\
\text { peptide-specific CTL }\end{array}$ & EC & Local control & 20 & Single & December 2016 & December 2019 \\
\hline NCT03200691 & Phase 2 & $\begin{array}{l}\text { SHR-1210 + } \\
\text { neoadjuvant } \\
\text { radiotherapy }\end{array}$ & ESCC & pCRR & 21 & Single & August 2017 & July 2020 \\
\hline NCT03187314 & Phase 2 & $\begin{array}{l}\text { SHR-1210 + } \\
\text { radiation }\end{array}$ & EC & Local control & 21 & Single & June 2017 & December 2019 \\
\hline \multicolumn{9}{|c|}{ Immunotherapy combined with neoadjuvant chemoradiotherapy/chemoradiotherapy } \\
\hline NCT01691625 & $\begin{array}{l}\text { Not } \\
\text { applicable }\end{array}$ & $\begin{array}{l}\text { Chemoradiation only } \\
\text { vs. } \\
\text { chemoradiotherapy } \\
\text { + DC-CIK } \\
\text { immunotherapy }\end{array}$ & EC & QOL & 50 & Single & September 2012 & December 2021 \\
\hline NCT04177875 & Phase 2 & $\begin{array}{l}\text { Teripalimab + } \\
\text { chemoradiation }\end{array}$ & EC & MPR; ORR & 44 & Single & May 2019 & April 2022 \\
\hline NCT03940001 & $\begin{array}{l}\text { Early } \\
\text { Phase } 1\end{array}$ & $\begin{array}{l}\text { Sintilimab + } \\
\text { neoadjuvant } \\
\text { chemoradiotherapy }\end{array}$ & ESCC & $\begin{array}{l}\text { toxicity; pCRR; } \\
\text { MPR }\end{array}$ & 20 & Single & May 2019 & May 2022 \\
\hline NCT04006041 & Phase 2 & $\begin{array}{l}\text { Toripalimab + } \\
\text { neoadjuvant } \\
\text { chemoradiotherapy }\end{array}$ & ESCC & $\mathrm{pCCR}$ & 44 & Single & June 2019 & December 2020 \\
\hline NCT04177875 & Phase 2 & $\begin{array}{l}\text { Teripalimab + } \\
\text { chemoradiation }\end{array}$ & EC & MPR; ORR & 44 & Single & May 2019 & April 2022 \\
\hline NCT04084158 & Phase 2 & $\begin{array}{l}\text { Chemoradiation vs. } \\
\text { triprizumab }+ \\
\text { chemoradiation }\end{array}$ & ESCC & PFS & 100 & Single & September 2019 & December 2021 \\
\hline \multicolumn{9}{|c|}{ Immunotherapy combined with targeted therapy } \\
\hline NCT03736863 & Phase 2 & $\begin{array}{l}\text { Apatinib + } \\
\text { SHR-1210 }\end{array}$ & $\mathrm{EC}$ & ORR & 45 & Single & April 2019 & April 2021 \\
\hline
\end{tabular}


TABLE 2 | Continued

\begin{tabular}{|c|c|c|c|c|c|c|c|c|}
\hline Trail ID & Phase & Design & Population & $\begin{array}{l}\text { Primary } \\
\text { endpoint }\end{array}$ & Enrollment & Center & Initiation date & $\begin{array}{l}\text { Estimated } \\
\text { completion date }\end{array}$ \\
\hline \multicolumn{9}{|c|}{ Immunotherapy combined with targeted therapy and chemotherapy } \\
\hline
\end{tabular}

GEJC, gastroesophageal junction carcinomas; EC, esophageal cancer; ESCC, esophageal squamous cell carcinoma; CAR-T, chimeric antigen receptor T-cell immunotherapy; TCR-T,

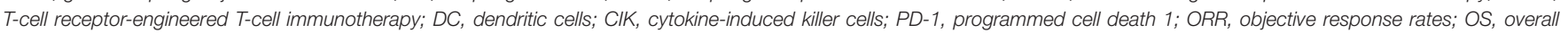

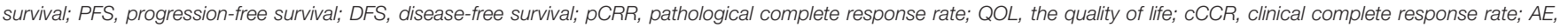
adverse events; MPR, major pathological response.

\section{CONCLUSIONS}

Although the incidence of EC is decreasing in the last few decades, it remains as one of the leading causes of cancer-related deaths in China. ESCC and EAC, two subtypes of EC, share very limited similarity in risk factors as well as genetic mutation profile, suggesting that they are actually two distinct diseases; thus, the treatment strategy and prognosis for these two EC subtypes could be quite different. Until now, the most efficient strategy to treat EC patients is combining esophagectomy and lymphadenectomy; therefore, early screening and diagnosis for EC patients are of utmost importance. Currently, the majority of EC patients are diagnosed at a late stage with local or distant metastasis, and many available therapies, including targeted therapy and immunotherapy, do not bring satisfying survival advantages for these patients as for other cancer populations. Combining different therapies together represents a promising strategy in the future for late-stage EC patients, although extensive clinical trials are demanded in a randomized, multi-center fashion. The comprehensive understanding of EC tumorigenesis is still lacking due to limited research systems, as most findings of EC development are generated from in vitro cultured EC cell lines. We, therefore, advocate newly emerged

\section{REFERENCES}

1. Bray F, Ferlay J, Soerjomataram I, Siegel RL, Torre LA, Jemal A. Global cancer statistics 2018: GLOBOCAN estimates of incidence and mortality worldwide for 36 cancers in 185 countries. CA Cancer J Clin. (2018) 68:394-424. doi: $10.3322 /$ caac. 21492

2. Lagergren J, Smyth E, Cunningham D, Lagergren P. Oesophageal cancer. Lancet. (2017) 390:2383-96. doi: 10.1016/S0140-6736(17)31462-9

3. Arnold M, Soerjomataram I, Ferlay J, Forman D. Global incidence of oesophageal cancer by histological subtype in 2012. Gut. (2015) 64:381-7. doi: 10.1136/gutjnl-2014-308124

4. Shibata A, Matsuda T, Ajiki W, Sobue T. Trend in incidence of adenocarcinoma of the esophagus in Japan, 1993-2001. Jpn J Clin Oncol. (2008) 38:464-8. doi: 10.1093/jjco/hyn064

5. Lin Y, Totsuka Y, He Y, Kikuchi S, Qiao Y, Ueda J, et al. Epidemiology of esophageal cancer in Japan and China. J Epidemiol. (2013) 23:233-42. doi: 10.2188/jea.JE20120162

6. He Y, Li D, Shan B, Liang D, Shi J, Chen W, et al. Incidence and mortality of esophagus cancer in China, 2008-2012. Chin J Cancer Res. (2019) 31:426-34. doi: $10.21147 /$ j.issn.1000-9604.2019.03.04 tools, such as EC patient-derived organoid (EC-PDO) (94, 95) and spontaneous EC animal models (96) to seek ultimate personalized therapy for EC patients.

\section{AUTHOR CONTRIBUTIONS}

JY and XL collected the data of clinical trials and drafted the manuscript. SC and XD coordinated and edited the drafting of the manuscript. KC and SR revised and edited the final version of the manuscript. All authors read and approved the final manuscript.

\section{FUNDING}

This work was supported by the startup funding of the Southern Medical University and National Natural Science Foundation of China Youth Project (81903097).

\section{ACKNOWLEDGMENTS}

We thank all our colleagues from the Department of Thoracic Surgery, Nanfang Hospital, for their kind suggestion and thoughtful discussion.

7. Vizcaino AP, Moreno V, Lambert R, Parkin DM. Time trends incidence of both major histologic types of esophageal carcinomas in selected countries, 1973-1995. Int J Cancer. (2002) 99:860-8. doi: 10.1002/ijc.10427

8. Castro C, Bosetti C, Malvezzi M, Bertuccio P, Levi F, Negri E, et al. Patterns and trends in esophageal cancer mortality and incidence in Europe (1980-2011) and predictions to 2015. Ann Oncol. (2014) 25:283-90. doi: 10.1093/annonc/mdt486

9. Islami F, Desantis CE, Jemal A. Incidence trends of esophageal and gastric cancer subtypes by race, ethnicity, and age in the United States, 19972014. Clin Gastroenterol Hepatol. (2019) 17:429-39. doi: 10.1016/j.cgh.2018. 05.044

10. Wang K, Johnson A, Ali SM, Klempner SJ, Bekaii-Saab T, Vacirca JL, et al. Comprehensive genomic profiling of advanced esophageal squamous cell carcinomas and esophageal adenocarcinomas reveals similarities and differences. Oncologist. (2015) 20:1132-9. doi: 10.1634/theoncologist.2015-0156

11. Cancer Genome Atlas Research N, Analysis Working Group: Asan U, Agency BCC, Brigham Women's H, Broad I, Brown U, et al. Integrated genomic characterization of oesophageal carcinoma. Nature. (2017) 541:16975. doi: 10.1038/nature20805 
12. Chen W, Zheng R, Zuo T, Zeng H, Zhang S, He J. National cancer incidence and mortality in China, 2012. Chin J Cancer Res. (2016) 28:1-11. doi: 10.3978/j.issn.1000-9604.2016.02.08

13. Chen W, Zheng R, Zhang S, Zeng H, Xia C, Zuo T, et al. Cancer incidence and mortality in China, 2013. Cancer Lett. (2017) 401:63-71. doi: 10.1016/j.canlet.2017.04.024

14. Chen W, Sun K, Zheng R, Zeng H, Zhang S, Xia C, et al. Cancer incidence and mortality in China, 2014. Chin J Cancer Res. (2018) 30:1-12. doi: 10.21147/j.issn.1000-9604.2018.01.01

15. Lan L, Zhao F, Cai Y, Wu RX, Meng Q. Epidemiological analysis on mortality of cancer in China, 2015. Zhonghua Liu Xing Bing Xue Za Zhi. (2018) 39:32-4. doi: 10.3760/cma.j.issn.0254-6450.2018.01.006

16. Zhou MG, Wang XF, Hu JP, Li GL, Chen WQ, Zhang SW, et al. [Geographical distribution of cancer mortality in China, 2004-2005]. Zhonghua Yu Fang Yi Xue Za Zhi. (2010) 44:303-8. doi: 10.3760/cma.j.issn.0253-9624.2010.04.006

17. Zeng H, Zheng R, Zhang S, Zuo T, Xia C, Zou X, et al. Esophageal cancer statistics in China, 2011: estimates based on 177 cancer registries. Thorac Cancer. (2016) 7:232-7. doi: 10.1111/1759-7714.12322

18. Zeng H, Chen W, Zheng R, Zhang S, Ji JS, Zou X, et al. Changing cancer survival in China during 2003-15: a pooled analysis of 17 population-based cancer registries. Lancet Glob Health. (2018) 6:e555-67. doi: 10.1016/S2214-109X(18)30127-X

19. Hou H, Meng Z, Zhao X, Ding G, Sun M, Wang W, et al. Survival of esophageal cancer in china: a pooled analysis on hospital-based studies from 2000 to 2018. Front Oncol. (2019) 9:548. doi: 10.3389/fonc.2019.00548

20. Zeng H, Zheng R, Guo Y, Zhang S, Zou X, Wang N, et al. Cancer survival in China, 2003-2005: a population-based study. Int J Cancer. (2015) 136:192130. doi: 10.1002/ijc. 29227

21. Li Y, Yu L, Na J, Li S, Liu L, Mu H, et al. Survival of cancer patients in Northeast China: analysis of sampled cancers from population-based cancer registries. Cancer Res Treat. (2017) 49:1106-13. doi: 10.4143/crt.2016.613

22. Wang J, Wu N, Zheng QF, Yan S, Lv C, Li SL, et al. Evaluation of the 7 th edition of the TNM classification in patients with resected esophageal squamous cell carcinoma. World J Gastroenterol. (2014) 20:18397-403. doi: 10.3748/wjg.v20.i48.18397

23. Hou X, Wei JC, Fu JH, Wang X, Zhang LJ, Lin P, et al. Proposed modification of the seventh American joint committee on cancer staging system for esophageal squamous cell carcinoma in Chinese patients. Ann Surg Oncol. (2014) 21:337-42. doi: 10.1245/s10434-013-3265-2

24. Chen MQ, Xu BH, Zhang YY. Analysis of prognostic factors for esophageal squamous cell carcinoma with distant organ metastasis at initial diagnosis. $J$ Chin Med Assoc. (2014) 77:562-6. doi: 10.1016/j.jcma.2014.05.014

25. Chen JG, Chen HZ, Zhu J, Yang YL, Zhang YH, Huang PX, et al. Cancer survival in patients from a hospital-based cancer registry, China. J Cancer. (2018) 9:851-60. doi: 10.7150/jca.23039

26. Cancer IAFR. List of Classifications by Cancer Sites With Sufficient or Limited Evidence in Humans. Lyon: IARC (2015).

27. Kamangar F, Chow WH, Abnet CC, Dawsey SM. Environmental causes of esophageal cancer. Gastroenterol Clin North Am. (2009) 38:27-57, vii. doi: 10.1016/j.gtc.2009.01.004

28. Doll R, Peto R, Wheatley K, Gray R, Sutherland I. Mortality in relation to smoking: 40 years' observations on male British doctors. BMJ. (1994) 309:901-11. doi: 10.1136/bmj.309.6959.901

29. Wang QL, Xie SH, Li WT, Lagergren J. Smoking cessation and risk of esophageal cancer by histological type: systematic review and meta-analysis. J Natl Cancer Inst. (2017) 109:djx115. doi: 10.1093/jnci/djx115

30. Gammon MD, Schoenberg JB, Ahsan H, Risch HA, Vaughan TL, Chow WH, et al. Tobacco, alcohol, and socioeconomic status and adenocarcinomas of the esophagus and gastric cardia. J Natl Cancer Inst. (1997) 89:1277-84. doi: 10.1093/jnci/89.17.1277

31. Engel LS, Chow WH, Vaughan TL, Gammon MD, Risch HA, Stanford JL, et al. Population attributable risks of esophageal and gastric cancers. J Natl Cancer Inst. (2003) 95:1404-13. doi: 10.1093/jnci/djg047

32. Bagnardi V, Rota M, Botteri E, Tramacere I, Islami F, Fedirko V, et al. Light alcohol drinking and cancer: a meta-analysis. Ann Oncol. (2013) 24:301-8. doi: 10.1093/annonc/mds337

33. Islami F, Fedirko V, Tramacere I, Bagnardi V, Jenab M, Scotti L, et al. Alcohol drinking and esophageal squamous cell carcinoma with focus on light-drinkers and never-smokers: a systematic review and meta-analysis. Int J Cancer. (2011) 129:2473-84. doi: 10.1002/ijc.25885

34. Pan D, Su M, Zhang T, Miao C, Fu L, Yang L, et al. A distinct epidemiologic pattern of precancerous lesions of esophageal squamous cell carcinoma in a high-risk area of Huai'an, Jiangsu Province, China. Cancer Prev Res. (2019) 12:449-62. doi: 10.1158/1940-6207.CAPR-18-0462

35. Zhao F, Su JF, Lun SM, Hou YJ, Duan LJ, Wang NC, et al. Association between polymorphisms in the CYP1A1, CYP2E1 and GSTM1 genes, and smoking, alcohol and upper digestive tract carcinomas in a high-incidence area of northern China. Oncol Lett. (2019) 18:1267-77. doi: 10.3892/ol.2019.10455

36. Wu M, Zhao JK, Zhang ZF, Han RQ, Yang J, Zhou JY, et al. Smoking and alcohol drinking increased the risk of esophageal cancer among Chinese men but not women in a high-risk population. Cancer Causes Control. (2011) 22:649-57. doi: 10.1007/s10552-011-9737-4

37. Yang X, Chen X, Zhuang M, Yuan Z, Nie S, Lu M, et al. Smoking and alcohol drinking in relation to the risk of esophageal squamous cell carcinoma: a population-based case-control study in China. Sci Rep. (2017) 7:17249. doi: 10.1038/s41598-017-17617-2

38. Suo C, Yang Y, Yuan Z, Zhang T, Yang X, Qing T, et al. Alcohol intake interacts with functional genetic polymorphisms of aldehyde dehydrogenase (ALDH2) and alcohol dehydrogenase (ADH) to increase esophageal squamous cell cancer risk. J Thorac Oncol. (2019) 14:712-25. doi: 10.1016/j.jtho.2018.12.023

39. Freedman ND, Murray LJ, Kamangar F, Abnet CC, Cook MB, Nyren $\mathrm{O}$, et al. Alcohol intake and risk of oesophageal adenocarcinoma: a pooled analysis from the BEACON consortium. Gut. (2011) 60:1029-37. doi: 10.1136/gut.2010.233866

40. Jeurnink SM, Buchner FL, Bueno-De-Mesquita HB, Siersema PD, Boshuizen HC, Numans ME, et al. Variety in vegetable and fruit consumption and the risk of gastric and esophageal cancer in the European prospective investigation into cancer and nutrition. Int J Cancer. (2012) 131:E963-73. doi: $10.1002 / \mathrm{ijc} .27517$

41. Islami F, Ren JS, Taylor PR, Kamangar F. Pickled vegetables and the risk of oesophageal cancer: a meta-analysis. Br J Cancer. (2009) 101:1641-7. doi: 10.1038/sj.bjc.6605372

42. Qu X, Ben Q, Jiang Y. Consumption of red and processed meat and risk for esophageal squamous cell carcinoma based on a meta-analysis. Ann Epidemiol. (2013) 23:762-70.e761. doi: 10.1016/j.annepidem.2013.09.003

43. Zhu HC, Yang X, Xu LP, Zhao LJ, Tao GZ, Zhang C, et al. Meat consumption is associated with esophageal cancer risk in a meat- and cancer-histological-type dependent manner. Dig Dis Sci. (2014) 59:664-73. doi: 10.1007/s10620-013-2928-y

44. Castellsague X, Munoz N, De Stefani E, Victora CG, Castelletto R, Rolon PA. Influence of mate drinking, hot beverages and diet on esophageal cancer risk in South America. Int J Cancer. (2000) 88:658-64. doi: 10.1002/1097-0215(20001115)88:4<658::AID-IJC22>3.0.CO;2-T

45. Andrici J, Eslick GD. Hot food and beverage consumption and the risk of esophageal cancer: a meta-analysis. Am J Prev Med. (2015) 49:952-60. doi: 10.1016/j.amepre.2015.07.023

46. Tai WP, Nie GJ, Chen MJ, Yaz TY, Guli A, Wuxur A, et al. Hot food and beverage consumption and the risk of esophageal squamous cell carcinoma: a case-control study in a northwest area in China. Medicine. (2017) 96:e9325. doi: 10.1097/MD.0000000000009325

47. Chow WH, Finkle WD, Mclaughlin JK, Frankl H, Ziel HK, Fraumeni JF Jr. The relation of gastroesophageal reflux disease and its treatment to adenocarcinomas of the esophagus and gastric cardia. JAMA. (1995) 274:4747. doi: 10.1001/jama.1995.03530060048032

48. Lagergren J, Bergstrom R, Lindgren A, Nyren O. Symptomatic gastroesophageal reflux as a risk factor for esophageal adenocarcinoma. N Engl J Med. (1999) 340:825-31. doi: 10.1056/NEJM199903183401101

49. Ye W, Chow WH, Lagergren J, Yin L, Nyren O. Risk of adenocarcinomas of the esophagus and gastric cardia in patients with gastroesophageal reflux diseases and after antireflux surgery. Gastroenterology. (2001) 121:1286-93. doi: 10.1053/gast.2001.29569

50. Rubenstein JH, Taylor JB. Meta-analysis: the association of oesophageal adenocarcinoma with symptoms of gastro-oesophageal reflux. Aliment Pharmacol Ther. (2010) 32:1222-7. doi: 10.1111/j.1365-2036.2010.04471.x

51. O'doherty MG, Freedman ND, Hollenbeck AR, Schatzkin A, Abnet CC. A prospective cohort study of obesity and risk of oesophageal and gastric 
adenocarcinoma in the NIH-AARP diet and health study. Gut. (2012) 61, 1261-8. doi: 10.1136/gutjnl-2011-300551

52. Hoyo C, Cook MB, Kamangar F, Freedman ND, Whiteman DC, Bernstein $\mathrm{L}$, et al. Body mass index in relation to oesophageal and oesophagogastric junction adenocarcinomas: a pooled analysis from the International BEACON Consortium. Int J Epidemiol. (2012) 41:1706-18. doi: 10.1093/ije/dys176

53. Smith M, Zhou M, Whitlock G, Yang G, Offer A, Hui G, et al. Esophageal cancer and body mass index: results from a prospective study of 220,000 men in China and a meta-analysis of published studies. Int J Cancer. (2008) 122:1604-10. doi: 10.1002/ijc.23198

54. Wang SM, Fan JH, Jia MM, Yang Z, Zhang YQ, Qiao YL, et al. Body mass index and long-term risk of death from esophageal squamous cell carcinoma in a Chinese population. Thorac Cancer. (2016) 7:387-92. doi: $10.1111 / 1759-7714.12340$

55. Tran GD, Sun XD, Abnet CC, Fan JH, Dawsey SM, Dong ZW, et al. Prospective study of risk factors for esophageal and gastric cancers in the Linxian general population trial cohort in China. Int J Cancer. (2005) 113:45663. doi: $10.1002 /$ ijc. 20616

56. Islami F, Kamangar F, Nasrollahzadeh D, Aghcheli K, Sotoudeh M, AbediArdekani B, et al. Socio-economic status and oesophageal cancer: results from a population-based case-control study in a high-risk area. Int J Epidemiol. (2009) 38:978-88. doi: 10.1093/ije/dyp195

57. Lagergren J, Andersson G, Talback M, Drefahl S, Bihagen E, Harkonen J, et al. Marital status, education, and income in relation to the risk of esophageal and gastric cancer by histological type and site. Cancer. (2016) 122:207-12. doi: $10.1002 / \mathrm{cncr} .29731$

58. Jansson C, Johansson AL, Nyren O, Lagergren J. Socioeconomic factors and risk of esophageal adenocarcinoma: a nationwide Swedish casecontrol study. Cancer Epidemiol Biomarkers Prev. (2005) 14:1754-61. doi: 10.1158/1055-9965.EPI-05-0140

59. Salem ME, Puccini A, Xiu J, Raghavan D, Lenz HJ, Korn WM, et al. Comparative molecular analyses of esophageal squamous cell carcinoma, esophageal adenocarcinoma, and gastric adenocarcinoma. Oncologist. (2018) 23:1319-27. doi: 10.1634/theoncologist.2018-0143

60. Simba H, Kuivaniemi H, Lutje V, Tromp G, Sewram V. Systematic review of genetic factors in the etiology of esophageal squamous cell carcinoma in African populations. Front Genet. (2019) 10:642. doi: 10.3389 /fgene.2019.00642

61. Chen XX, Zhong Q, Liu Y, Yan SM, Chen ZH, Jin SZ, et al. Genomic comparison of esophageal squamous cell carcinoma and its precursor lesions by multi-region whole-exome sequencing. Nat Commun. (2017) 8:524. doi: 10.1038/s41467-017-00650-0

62. Lin DC, Wang MR, Koeffler HP. Genomic and epigenomic aberrations in esophageal squamous cell carcinoma and implications for patients. Gastroenterology. (2018) 154:374-89. doi: 10.1053/j.gastro.2017.06.066

63. Gao YB, Chen ZL, Li JG, Hu XD, Shi XJ, Sun ZM, et al. Genetic landscape of esophageal squamous cell carcinoma. Nat Genet. (2014) 46:1097-102. doi: $10.1038 / \mathrm{ng} .3076$

64. Lin DC, Hao JJ, Nagata Y, Xu L, Shang L, Meng X, et al. Genomic and molecular characterization of esophageal squamous cell carcinoma. Nat Genet. (2014) 46:467-73. doi: 10.1038/ng.2935

65. Song Y, Li L, Ou Y, Gao Z, Li E, Li X, et al. Identification of genomic alterations in oesophageal squamous cell cancer. Nature. (2014) 509:91-5. doi: 10.1038/nature13176

66. Sasaki Y, Tamura M, Koyama R, Nakagaki T, Adachi Y, Tokino T. Genomic characterization of esophageal squamous cell carcinoma: insights from next-generation sequencing. World J Gastroenterol. (2016) 22:2284-93. doi: 10.3748 /wjg.v22.i7.2284

67. Ko JM, Ning L, Zhao XK, Chai AWY, Lei LC, Choi SSA, et al. BRCA2 loss-of-function germline mutations are associated with esophageal squamous cell carcinoma risk in Chinese. Int J Cancer. (2019) 146:1042-51. doi: 10.1002/ijc.32619

68. Golyan FF, Druley TE, Abbaszadegan MR. Whole-exome sequencing of familial esophageal squamous cell carcinoma identified rare pathogenic variants in new predisposition genes. Clin Transl Oncol. (2019) 22:681-93. doi: 10.1007/s12094-019-02174-z

69. Guo X, Tang Y, Zhu W. Distinct esophageal adenocarcinoma molecular subtype has subtype-specific gene expression and mutation patterns. BMC Genomics. (2018) 19:769. doi: 10.1186/s12864-0185165-0

70. Sethi N, Kikuchi O, Mcfarland J, Zhang Y, Chung M, Kafker N, et al. Mutant p53 induces a hypoxia transcriptional program in gastric and esophageal adenocarcinoma. JCI Insight. (2019) 4:e128439. doi: $10.1172 /$ jci.insight. 128439

71. Suh YS, Han DS, Kong SH, Lee HJ, Kim YT, Kim WH, et al Should adenocarcinoma of the esophagogastric junction be classified as esophageal cancer? A comparative analysis according to the seventh AJCC TNM classification. Ann Surg. (2012) 255:908-15. doi: 10.1097/SLA.0b013e31824beb95

72. Dulak AM, Stojanov P, Peng S, Lawrence MS, Fox C, Stewart C, et al. Exome and whole-genome sequencing of esophageal adenocarcinoma identifies recurrent driver events and mutational complexity. Nat Genet. (2013) 45:47886. doi: $10.1038 /$ ng. 2591

73. Lordick F, Mariette C, Haustermans K, Obermannova R, Arnold D. Oesophageal cancer: ESMO clinical practice guidelines for diagnosis, treatment and follow-up. Ann Oncol. (2016) 27:v50-7. doi: $10.1093 / \mathrm{annonc} / \mathrm{mdw} 329$

74. Tu CC, Hsu PK. The frontline of esophageal cancer treatment: questions to be asked and answered. Ann Trans Med. (2018) 6:83. doi: $10.21037 /$ atm.2017.10.31

75. Group MRCOCW. Surgical resection with or without preoperative chemotherapy in oesophageal cancer: a randomised controlled trial. Lancet. (2002) 359:1727-33. doi: 10.1016/S0140-6736(02)08651-8

76. Xu XH, Peng XH, Yu P, Xu XY, Cai EH, Guo P, et al. Neoadjuvant chemotherapy for resectable esophageal carcinoma: a meta-analysis of randomized clinical trials. Asian Pac J Cancer Prev. (2012) 13:103-10. doi: 10.7314/APJCP.2012.13.1.103

77. Kidane B, Coughlin S, Vogt K, Malthaner R. Preoperative chemotherapy for resectable thoracic esophageal cancer. Cochrane Database Syst Rev. (2015) 2015:CD001556. doi: 10.1002/14651858.CD001556.pub3

78. Arnott SJ, Duncan W, Gignoux M, Girling DJ, Hansen HS, Launois B, et al. Preoperative radiotherapy in esophageal carcinoma: a meta-analysis using individual patient data (oesophageal cancer collaborative group). Int J Radiat Oncol Biol Phys. (1998) 41:579-83. doi: 10.1016/S0360-3016(97)00569-5

79. Pasquali S, Yim G, Vohra RS, Mocellin S, Nyanhongo D, Marriott P, et al. Survival after neoadjuvant and adjuvant treatments compared to surgery alone for resectable esophageal carcinoma. Ann Surg. (2017) 265:481-91. doi: 10.1097/SLA.0000000000001905

80. Dutton SJ, Ferry DR, Blazeby JM, Abbas H, Dahle-Smith A, Mansoor W, et al. Gefitinib for oesophageal cancer progressing after chemotherapy (COG): a phase 3, multicentre, double-blind, placebo-controlled randomised trial. Lancet Oncol. (2014) 15:894-904. doi: 10.1016/S1470-2045(14) 70024-5

81. Janmaat ML, Gallegos-Ruiz MI, Rodriguez JA, Meijer GA, Vervenne WL, Richel DJ, et al. Predictive factors for outcome in a phase II study of gefitinib in second-line treatment of advanced esophageal cancer patients. J Clin Oncol. (2006) 24:1612-9. doi: 10.1200/JCO.2005.03.4900

82. Kato K, Doi $\mathrm{T}$, Kojima $\mathrm{T}$, Hara $\mathrm{H}$, Takahashi $\mathrm{S}$, Muro $\mathrm{K}$, et al. Phase II study of BKM120 in patients with advanced esophageal squamous cell carcinoma (EPOC1303). J Clin Oncol. (2017) 35:4069. doi: 10.1200/JCO.2017.35.15_suppl.4069

83. Suntharalingam M, Winter K, Ilson D, Dicker AP, Kachnic L, Konski A, et al. Effect of the addition of cetuximab to paclitaxel, cisplatin, and radiation therapy for patients with esophageal cancer: the NRG oncology RTOG 0436 phase 3 randomized clinical trial. JAMA Oncol. (2017) 3:1520-8. doi: 10.1001/jamaoncol.2017.1598

84. Bang YJ, Van Cutsem E, Feyereislova A, Chung HC, Shen L, Sawaki A, et al. Trastuzumab in combination with chemotherapy versus chemotherapy alone for treatment of HER2-positive advanced gastric or gastro-oesophageal junction cancer (ToGA): a phase 3, open-label, randomised controlled trial. Lancet. (2010) 376:687-97. doi: 10.1016/S0140-6736(10)61121-X

85. Tabernero J, Hoff PM, Shen L, Ohtsu A, Shah MA, Cheng K, et al. Pertuzumab plus trastuzumab and chemotherapy for HER2-positive metastatic gastric or gastro-oesophageal junction cancer (JACOB): final analysis of a doubleblind, randomised, placebo-controlled phase 3 study. Lancet Oncol. (2018) 19:1372-84. doi: 10.1016/S1470-2045(18)30481-9 
86. Pardoll DM. The blockade of immune checkpoints in cancer immunotherapy. Nature Reviews Cancer. (2012) 12:252-64. doi: 10.1038/nrc3239

87. Robert C, Ribas A, Wolchok JD, Hodi FS, Hamid O, Kefford R, et al. Anti-programmed-death-receptor-1 treatment with pembrolizumab in ipilimumab-refractory advanced melanoma: a randomised dosecomparison cohort of a phase 1 trial. Lancet. (2014) 384:1109-17. doi: 10.1016/S0140-6736(14)60958-2

88. Doi T, Piha-Paul SA, Jalal SI, Saraf S, Lunceford J, Koshiji M, et al. Safety and antitumor activity of the anti-programmed death-1 antibody pembrolizumab in patients with advanced esophageal carcinoma. J Clin Oncol. (2018) 36:61-7. doi: 10.1200/JCO.2017.74.9846

89. Shah MA, Kojima T, Hochhauser D, Enzinger P, Raimbourg J, Hollebecque A, et al. Efficacy and safety of pembrolizumab for heavily pretreated patients with advanced, metastatic adenocarcinoma or squamous cell carcinoma of the esophagus: the phase 2 KEYNOTE-180 study. JAMA Oncol. (2019) 5:546-50. doi: 10.1001/jamaoncol.2018.5441

90. Mayes PA, Hance KW, Hoos A. The promise and challenges of immune agonist antibody development in cancer. Nat Rev Drug Discov. (2018) 17:50927. doi: $10.1038 / \mathrm{nrd} .2018 .75$

91. Havel JJ, Chowell D, Chan TA. The evolving landscape of biomarkers for checkpoint inhibitor immunotherapy. Nat Rev Cancer. (2019) 19:133-50. doi: 10.1038/s41568-019-0116-x

92. Ralph C, Elkord E, Burt DJ, O'dwyer JF, Austin EB, Stern PL, et al. Modulation of lymphocyte regulation for cancer therapy: a phase II trial of tremelimumab in advanced gastric and esophageal adenocarcinoma. Clin. Cancer Res. (2010) 16:1662-72. doi: 10.1158/1078-0432.CCR-09-2870
93. Janjigian YY, Bendell J, Calvo E, Kim JW, Ascierto PA, Sharma P, et al CheckMate-032 study: efficacy and safety of nivolumab and nivolumab plus ipilimumab in patients with metastatic esophagogastric cancer. J Clin Oncol. (2018) 36:2836-44. doi: 10.1200/JCO.2017.76.6212

94. Li X, Francies HE, Secrier M, Perner J, Miremadi A, Galeano-Dalmau N, et al. Organoid cultures recapitulate esophageal adenocarcinoma heterogeneity providing a model for clonality studies and precision therapeutics. Nat Commun. (2018) 9:2983. doi: 10.1038/s41467-018-05190-9

95. Kijima T, Nakagawa H, Shimonosono M, Chandramouleeswaran PM, Hara $\mathrm{T}$, Sahu V, et al. Three-dimensional organoids reveal therapy resistance of esophageal and oropharyngeal squamous cell carcinoma cells. Cell Mol Gastroenterol Hepatol. (2019) 7:73-91. doi: 10.1016/j.jcmgh.2018.09.003

96. Nair DV, Reddy AG. Laboratory animal models for esophageal cancer. Vet World. (2016) 9:1229-32. doi: 10.14202/vetworld.2016.1229-1232

Conflict of Interest: The authors declare that the research was conducted in the absence of any commercial or financial relationships that could be construed as a potential conflict of interest.

Copyright (c) 2020 Yang, Liu, Cao, Dong, Rao and Cai. This is an open-access article distributed under the terms of the Creative Commons Attribution License (CC BY). The use, distribution or reproduction in other forums is permitted, provided the original author(s) and the copyright owner(s) are credited and that the original publication in this journal is cited, in accordance with accepted academic practice. No use, distribution or reproduction is permitted which does not comply with these terms. 